\title{
Negotiating at the Boundary: \\ Patinkin vs. Phipps
}

\author{
Ted Gayer and E. Roy Weintraub
}

Economists and mathematicians themselves do not fully understand the way they have negotiated the more or less rigid boundary that separates their disciplines. Scholars in both fields have contested the role of mathematics in economics and the legitimate place of mathematics in economics; moreover, the uses that economists have made of mathematics are many and varied and have hardly been stable.

Mathematical economists often claim that one can translate between mathematics and economics. Following his mathematical mentor's mentor, J. Willard Gibbs, Paul Samuelson claimed in Foundations of Economic Analysis that "mathematics is a language." This belief in translation is often accompanied by a realist epistemology that posits that (1) the economy exists autonomously; (2) it can be represented by ordinary language propositions; and (3) the language of mathematics is useful in translating and operating with those propositions characterizing that autonomous existence. An implied corollary of this position is that any disagreement between an economist and a mathematician on the nature of a mathematical proof is due to a misunderstanding of the assumptions or the logical reasoning of the proof. And any disagreement on the economic implications of the mathematical proof is due to mistranslation or a lack of understanding of the underlying economic reality.

Correspondence may be addressed to Ted Gayer, 140 Warren Hall, Berkeley, CA 94720. Ted Gayer is a Robert Wood Johnson scholar in health policy research at the University of California, Berkeley, and an assistant professor of public policy at Georgetown University. E. Roy Weintraub is a professor of economics at Duke University.

History of Political Economy 32:3 @ 2000 by Duke University Press. 
Nevertheless, a number of studies document communication failures between mathematicians and economists. The most prominent of such studies detail the failures of economists to comprehend what mathematicians are trying to tell them about their work. For example, Bruna Ingrao and Giorgio Israel (1990) have discussed the problems Vilfredo Pareto had understanding the criticisms made of his work by Vito Volterra. Philip Mirowski (1989, 243-48) has examined the failure of Léon Walras to make sense of the letters from Hermann Laurent, who had tried to ask Walras about the nature of the integrating factor in the equilibrium conditions for marginal utility: a discussion that went nowhere and that ended when Walras "started suggesting to others that Laurent was part of a plot against him" (245).

In this article we shall instead explore the attempt of a mathematician to work within the economics community. The correspondence between the economist Don Patinkin and the mathematician Cecil Phipps exhibits the process by which members of these different disciplinary communities attempt to reconcile differences. ${ }^{1}$ Within their correspondence, Patinkin and Phipps discuss the validity of a mathematical proof that emerged in Patinkin's economic research. Their correspondence sheds light on the complexity of achieving a common understanding about the role of assumptions, the nature of proof, and the meaning of mathematical modeling-issues that challenge the belief that mathematics can be translated into economics.

\section{Introducing Don Patinkin}

Don Patinkin was born in Chicago, Illinois, in 1922. In his posthumously published paper "The Training of an Economist" (1995), Patinkin recalled that before entering college his vocational aptitude results "showed a high aptitude for mathematics. But we were still living in the shadow of the Great Depression and everyone knew that mathematicians went hungry. So the advice to me was to become a statistician-with the explanation that a statistician was a mathematician who could make a living" (359). Patinkin went on to receive his bachelor's degree in 1943 (entering as a third-year student in 1941), his master's degree in 1945, and his Ph.D. in 1947-all from the University of Chicago. He

1. Our discussion is based on material in the Don Patinkin Papers, located in the Special Collections Library at Duke University. 
then held teaching positions from 1946 to 1948 at the University of Chicago, rising to the rank of assistant professor. After spending a year as an associate professor at the University of Illinois, he immigrated to Israel in 1949 and there spent the remainder of his career at the Hebrew University in Jerusalem, eventually becoming its president.

Because we will be concerned with understanding Patinkin's correspondence with a mathematician, it is useful to discuss the kind of mathematical training that Patinkin received as a graduate student at the University of Chicago. Patinkin's primary teacher of graduate economic theory was Oscar Lange, who taught systematic courses in microeconomics and macroeconomics. "But Lange's most valuable course for me was the one on Mathematical Economics (i.e., what was then called mathematical economics!). Here he systematically took us through the Mathematical Appendix of Hicks's Value and Capital (1939), as well as Paul Samuelson's path-breaking article on 'The stability of equilibrium' (1941), subsequently reproduced as chapter 9 of the latter's Foundations of Economic Analysis (1947). My lecture notes from this course served me as a 'reference volume' for many years to come" (Patinkin 1995, 371-72).

We thus see that Patinkin, taught by Lange (who was mathematically quite adept), was working through some fairly sophisticated material rather early in his graduate career. Moreover, Patinkin's graduate career roughly corresponded to the period in which the Cowles Commission took hold at Chicago. In 1943, shortly after Jacob Marschak's arrival, "Ted Anderson, Trygve Haavelmo, Leo Hurwicz, Lawrence Klein, Tjalling Koopmans, Herman Rubin, and (somewhat later) Kenneth Arrow had joined the staff-some of them with joint appointments in the Department" (375). Thus Patinkin had contact with future Nobel laureates Klein, Koopmans, and Arrow, and was able to interact, on a regular basis, with a group of extremely mathematically sophisticated economists. Indeed, Patinkin received an SSRC fellowship for 1946-47 that enabled him to serve as a junior member of the Cowles Commission while he wrote his doctoral thesis, and he spent the following year at Cowles as a research associate.

Patinkin was not a mathematician. Nor was he an applied mathematician. However, from the perspective of the discipline of economics at that time, Patinkin would have been regarded as a hotshot mathematical economist. After all, there were very few places in America where mathematics was even regarded as appropriate for students of economics: the 
University of Chicago stood out among other institutions in this regard, even though with Harold Hotelling at Columbia, Paul Samuelson moving to MIT, and Griffith Evans at Berkeley, it was possible to receive training in mathematical economics elsewhere. But Chicago was almost unique at that time in having a large and active group to defend those interests. In fact, when Koopmans succeeded Marschak as research director of Cowles, he began making overtures to the eminent Chicago mathematics department to establish a mathematical statistics unit. If one was interested in mathematical economics in the United States in the 1940s, the graduate program at the University of Chicago was the place to pursue this interest.

Patinkin received his mathematical instruction primarily from Marschak. Under Marschak he took "an advanced graduate course in mathematical economics devoted to solving the problems in the second half of R. G. D. Allen's Mathematical Analysis for Economists (1938)" (Patinkin 1995, 375). He was the only student in that class and thus, in effect, had a mathematics tutorial from Marschak. It was this connection that lead Patinkin to seek out Marschak to be chair of his doctoral thesis committee.

Patinkin's dissertation developed from a graduate student paper on market-adjusting and inventory equations. With the encouragement of H. Gregg Lewis, in 1947 he began asking questions about the possibility of interpreting involuntary unemployment as labor being off its supply curve. Although his thesis committee consisted of Marschak (chairperson), Lewis, Paul Douglas, and Theodore O. Yntema, only Marschak and Lewis were really involved in his dissertation as advisors (379); the former brought the strength of mathematical modeling, while the latter was developing his strengths in labor economics:

The thesis consisted of two parts: the first dealing with the mathematical consistency of a general-equilibrium system with money; and the second with unemployment interpreted as the manifestation of an inconsistent system. . . I I still remember my excitement when I thought of interpreting [involuntary unemployment] in terms of an inconsistency in the system which prevented it from reaching an equilibrium position. (379)

As Patinkin notes, "Practically all of the first part of my thesis appeared in two Econometrica articles: 'Relative prices, Say's Law, and the demand for money' (1948) and 'The indeterminacy of absolute prices 
in classical monetary theory' (1949)" (380). The 1948 article and the first three parts of the 1949 one were more or less unchanged from the thesis. "These first three parts were primarily devoted to demonstrating the invalidity of the traditional dichotomy of general-equilibrium theory between the determination of equilibrium relative prices, on the one hand, and the equilibrium absolute price of [sic] level, on the other. . . However, the last ten paragraphs of this part of the article-which presents what I then termed a 'modified classical system,' in which there was no such dichotomy, but in which the classical neutrality of money à la quantity theory nevertheless held-did not appear in the original thesis" (380-81). Patinkin recalled that those ten paragraphs were, for him, the heart of the argument: "I still have vivid memories of the moment of truth when everything suddenly fell into place: when after long being troubled by the problem, I suddenly realized that the economically meaningful way for the commodity demand equations to depend on the absolute price level (and thus to avoid the invalid dichotomy) without violating the neutrality of money was to have them depend on the real value of money balances" (381).

Patinkin was later to reflect that "like most doctoral students (then, and I'm afraid even more so now), I attributed too much importance to technique and formal mathematical analysis. And so my thesis gave much emphasis to the rigorous derivation of theorems from definitions, assumptions, and preliminary lemmas, while devoting inadequate attention to the economic interpretation of the analysis" (383). Yet he notes that the last ten paragraphs of the 1949 article were different in that they contained an economic interpretation of the mathematical results. Consequently, the heart of that 1949 Econometrica article, those ten paragraphs, set the stage for Patinkin's own reevaluation of the interconnections between mathematics and economics:

In the years following my 1949 article, I gradually developed the philosophy that the mathematical analysis of any economic problem is not complete until it is given an intuitively appealing economic interpretation. From experience over the years I also learned that when there was a contradiction between the mathematics and the intuition, it is not always the intuition that was at fault, but frequently an implicit (and sometimes explicit) misguided assumption in the mathematics. Thus resorting to intuition as well as mathematics provides a most useful check on the analysis. It is a way of carrying out a fruitful 
dialogue with oneself. And it is the dialogue that I later carried out between the text and mathematical appendix of Money, Interest, and Prices. (383)

While writing his two Econometrica articles that set out the major results of his thesis, Patinkin became committed to the new state of Israel and a career away from the United States. Eventually he would become widely known among economists for his work on the neoclassical synthesis, which reached its pinnacle with his 1956 book Money, Interest, and Prices. But in the 1940s he was a young and very confident economist. He had just been trained and educated at the intellectual center of the American economics community-the American mathematical economics community — and he was looking to make his mark.

\section{Introducing Cecil G. Phipps}

The 1955 edition of American Men of Science has telegraphic biographical information on Cecil Glenn Phipps. He was born in Skidmore, Missouri, on 24 July 1895 , received his bachelor's degree in mathematics from the University of Montana in 1921, and was an instructor and assistant in mathematics at the University of Minnesota from 1921 to 1924, where he received his master's degree in 1924. Phipps then went to the University of Florida as an instructor from 1924 to 1927, going on leave to return to Minnesota to receive his Ph.D. in 1928, returning thereafter to Florida with the rank of assistant professor. Phipps's doctoral dissertation concerned "problems in approximation by function of given continuity." This exercise in mathematical analysis, approximation theory, examined how an arbitrary function could be approximated by a function of $n$-times continuous differentiability. He obtained the rank of associate professor in 1929 and professor in 1943. In that 1955 American Men of Science volume he lists his areas of interest as "approximation of functions of real variables" and "foundations of mathematical economics." Phipps left Florida for Tennessee Technological University in 1960.2

The notice of the April 1933 meeting of the Mathematical Association of America (MAA), Southeastern Section, includes a paper by Phipps titled "Subfreshmen Mathematics." During the same period, the

2. We are extremely grateful to Professor Paul Ehrlich of the University of Florida for providing much of the information on Phipps. 
catalog of the University of Florida showed that Phipps "is teaching plane trigonometry and solid geometry, elementary mathematical analysis, integral calculus, and advanced topics in calculus." Later, on the eve of World War II, we find Phipps teaching a general science course, "Man and the Physical World." Additional material on Phipps comes from Paul Ehrlich's history of the University of Florida mathematics department. ${ }^{3}$ The first mention of Phipps occurs in chapter 5 of this history. Ehrlich notes with some surprise that "a check of the Mathematical Reviews author index for 1940-1959 reveals that Cecil G. Phipps's research area was mathematical economics. It is interesting to note that a paper Phipps published in 1952 on 'Money in the Utility Function' received a Mathematics Review report by the eminent mathematical economist Kenneth Arrow.' In chapter 8 of his document, Ehrlich mentions that Robert George Blake received a master's degree in May 1945 under Phipps's supervision. Blake's master's thesis was titled "Circular Arrangement" and was written in conjunction with what was referred to as the Elasticity Theory Group. We also have a reference, among a group of recollections of elderly Gainesville residents in that history, that a Mrs. Pirenian grew up in Gainesville, and "as a Gainesville high school junior, she valued the privilege of studying geometry under Mrs. Dorothy Phipps, wife of Professor Cecil Phipps of the University of Florida mathematics department" (Ehrlich n.d.).

In an interview that Professor Franklin W. Kokomoor gave to the Florida Oral History Project concerning his joining the University of Florida mathematics department in 1927, he recalled the following:

When I first came as I said in my notes that I gave you there, there were only four of us in the department and three of us were new. Two others [one of course was Phipps] besides myself, just new. We taught fifteen, eighteen hours a week of class work, and that was the full contents of our mathematics offering here. But in the course of time, as we got more students and new colleges, and new colleges needed new mathematical services and so on, we kept on growing until I retired. . . . The student enrollment in 1927 was just over 2,000, so you see we were a small and close-knit school. The professors developed strong ties of loyalty and pride in their university, perhaps

3. This history is published on the World Wide Web at http://www.math.ufl.edu/ theral/ mathhist.html. Owing to the format of the document, we regretfully cannot provide page numbers for the passages that we quote or draw from. 
because each of us became intimately involved in campus activities, as well as teaching.

Apparently, the starting salary for Phipps as an assistant professor in 1927 would have been the same as Kokomoor's, \$2,500 a year.

In Professor Charles Crow's manuscript on the early history of the University of Florida (drawn on by Ehrlich) there is a reference to a monthly faculty discussion club, the Atheneum, already established by the time of the Sledd presidency in Lake City, prior to the move of the campus to Gainesville: "Members would work up lectures on subjects outside their academic specialties for presentation to the others at these monthly meetings. Professor Samuel Gould Sadler informed me that Professors Franklin Kokomoor and Cecil Phipps had been participants in this Atheneum Club; Phipps recruited Sadler into membership" (Ehrlich n.d.). Phipps's interests thus extended beyond mathematics, although they may have been more engaged the closer the subjects were to mathematics, a hardly surprising observation. Yet as we will see later in this article, Phipps frequently referred, in his letters, to his membership in a group of scholars who read economics papers as critics. In William Gilbert Miller's 1951 Ph.D. dissertation, which we believe is the only dissertation supervised by Phipps, there are frequent references to "Unpublished Notes on Econometrics," which consists of Phipps's "lectures and papers on the subject..., with contributions being made by Dr. G. B. Lang, Dr. M. D. Anderson, Mr. Ernest Lytle, Mr. R. N. Conkling, Mr. H. E. Whitsett and the author" (Miller 1951, iii). This group appears to have been drawn from individuals-faculty and graduate students-who had interests in econometrics and statistics. ${ }^{4}$ Some of the individuals may have had cross-connections with Phipps from his involvement in the Atheneum club.

Miller's dissertation, "The Mathematics of Production and Consumption in a Static Economy," reflects many of Phipps's views and even his words, as we shall see when we come to examine Phipps's correspondence. In the preface Miller writes of the "errors and misconceptions" that occur in the new science of mathematical analysis as applied to economics. "Nowhere in the literature have I been able to find a complete and correct mathematical treatment of the general case of production and consumption" (ii). Miller states that "mathematics when correctly used

4. According to Lytle's son, Lytle went on to teach econometrics and statistics at the Florida Institute of Technology. His specialty appears to have been Monte Carlo analysis (Lytle 1998). 
provides the economist with a powerful and versatile tool, but the rules governing its use are rigid. If the economist is to support his argument with mathematical methods, he must adhere strictly to the mathematical rules" (ii). As we will see, this belief in the sanctity of mathematics, and the misuses of mathematics by economists, was certainly held by Phipps. ${ }^{5}$

Phipps's interest in mathematical economics seems to have taken hold in the late 1940s and it continued through the 1950s. He appears not to have published anything in mathematics in that period, and with the appointment of an outsider, John Maxfield, as the new department chair charged to make appointments of young research faculty, Phipps became increasingly marginalized within the department. Memories of older faculty confirm Phipps's displeasure about the Maxfield appointment; indeed he resigned in protest over it in 1960 and accepted the invitation of a former Florida graduate student, Ralph C. Boles, who at that time was chair of the mathematics department at Tennessee Technological University, to join the Tennessee Tech faculty. He taught at Tennessee Tech for about five years, giving mostly upper-level courses and master's-level courses, primarily in mathematical analysis.

A former colleague at Tennessee Tech, Reginald Mazeres, recalled Phipps quite clearly. "It is obvious that at one time he'd been a brilliant man." However, "Phipps was not an easy man to get along with." 6 He was a good conversationalist and extremely opinionated. In the Tennessee Tech years, he had problems with both people and mathematics: "Some of his work was off beat," Mazeres stated. Mazeres recalled that at an MAA regional meeting at Emory University in 1966, Phipps presented a

5. There are many other echoes of Phipps in Miller's dissertation. For example, Miller describes the difference between dependent and independent functions (33-35), which Phipps discusses in his correspondence with Patinkin. Also contained in Miller's dissertation (51) is Phipps's critique of Tintner 1948, which we will discuss in the next section. Most striking is the similar tone of displeasure the two mathematicians share concerning the use of mathematics in economics.

6. We find further evidence of Phipps's cantankerous personality from a letter we received, via Paul Ehrlich, from Professor John L. Tilley, one of Phipps's former students. Tilley relates Phipps's displeasure with Tilley's explanation of the Fundamental Theorem of Calculus during his Ph.D. oral exams. Tilley writes, "The next day I went to his office and asked him what was his statement of the theorem. He had a stack of about 8 new Calculus texts on his desk. He told me that he would show me the theorem from one of them. He took the top one off and looked up the theorem. He read it to himself and tossed the book into the waste can. He did that with each of the remaining books! He was not satisfied with any of the statements of the theorem. I never did find out exactly what he wanted as he was so unhappy with those texts that he walked out of his office after throwing them all in the trash." 
paper on the empty set. It was there, in the discussion, that "some former colleagues of Phipps, University of Florida mathematicians, gave him a rough time. . . . They were extremely rude" (Mazeres 1998). Phipps apparently had an obsession with the empty set and would object in departmental seminars at Tennessee Tech when a mathematician wrote down the symbol for the empty set. He argued that since the empty set had no elements, it could not be characterized, and therefore it could not be used: since no one had any positive idea of nothingness, nothing itself could not be characterized. Putting the most positive possible spin on Phipps's argument, his then chair told us that Phipps argued that "if a set is empty, it has no elements and thus there's nothing to say about it" (Boles 1998).

\section{Phipps in Economics}

As background to the Patinkin-Phipps correspondence, we must understand that Cecil Phipps focused much of his attention on reviewing applied mathematical work. As already noted, he was a member of a group of mathematicians and statisticians that sought to make a thorough examination of the existing literature of applied mathematics and to point out occurrences of unsound mathematics. In a letter to Don Patinkin dated 20 December 1949 he wrote:

I examine [applied work] for soundness of the mathematics in them. If it is faulty, the article is worthless until the defect is corrected. When I read an article or a book whose results are based on mathematical deductions, I expect the same quality of mathematics as I would expect in a master's or doctor's thesis.

Phipps's emphasis on examining work in applied mathematics led him to publish three notes, between 1950 and 1952, on what he saw as mathematical inaccuracies in articles by Don Patinkin, Gerhard Tintner, and Milton Friedman. ${ }^{7}$ On 16 February 1950 he expressed his disgust with these papers to the editor of Econometrica, William Simpson:

My feelings on this matter are intense; some might say, bitter. . . I I am shocked at the misuse and abuse of the prestige of mathematics in reaching conclusions not logically justified by the given assumptions, especially when the "proof" is demonstrably false. . . It would save

7. The articles he criticized were Patinkin 1948, Tintner 1948, and Friedman 1952b. 
embarrassment to everyone (and printing costs) if every article in Econometrica were to receive before publication the same scrutiny which I am giving these articles after publication.

Phipps's first foray into economics was his one-page "Note on Tintner's 'Homogeneous Systems'" (Phipps 1950b). In it Phipps corrected theorem 3 of Tintner 1948, which claimed the following:

A function $f$ is assumed to be homogeneous of zero degree in the variables $u_{1}, u_{2}, \ldots, u_{m}$. These variables are themselves functions of the $M$ variables $v_{1}, v_{2}, \ldots, v_{m}$. The function $f$ remains homogeneous of zero degree in the new variables $v_{1}, v_{2}, \ldots, v_{m}$ if the old variables $u_{1}, u_{2}, \ldots, u_{m}$ are homogeneous functions of the same arbitrary degree in the variables $v_{1}, v_{2}, \ldots, v_{m}$. (Tintner 1948, 277)

Phipps correctly points out that the conditions for this theorem are sufficient, but they are not necessary. He uses a simple example to demonstrate his point:

Let $f(x, a)=g(x)\left[a_{2}-a_{1}\right] / a_{3} \ldots$ Then $f$ is homogeneous of degree zero in the $a$. Next let $a_{1}=c_{1}+5, a_{2}=c_{2}+5$, and $a_{3}=c_{3}$. After this substitution, $f(x, c)$ will be homogeneous of zero degree in the $c$ although the $a$ were not homogeneous of any degree in the c. (Phipps 1950b, 63)

Phipps's concern with Patinkin, which we will discuss in detail below, dates from the time he published a note on Patinkin in Econometrica in 1950 (Phipps 1950a). As is usual practice for writings by mathematicians, that Econometrica paper was itself reviewed in Mathematical Reviews. The reviewer, M. P. Stoltz, wrote that "several deductions are drawn from the joint assumptions of perfect competition and utility maximization as a behavior rule.... it is now argued that Patinkin ... finds the classical system inconsistent because of contradictory assumptions. ... The author's criticism seems invalid to the reviewer" (Stoltz 1951, 530; emphasis added).

Phipps's paper, "Money in the Utility Function" (Phipps 1952b), concerned the Patinkin themes in more detail, and it also received a notice in Mathematical Reviews, a notice that Professor Ehrlich had thought surprising. The reviewer, Kenneth Arrow (!), pointed out that Phipps made "the utility function depend on the following variables: the rates of consumption of commodities (the usual argument); the amounts 
of each commodity which could be purchased with a stock of Money; the amounts of each commodity which could be purchased with a stock of invested Savings; and the stocks of commodities held by the individual" (Arrow 1954, 366).

In that same year Phipps (1952a) criticized the mathematical reasoning used in Friedman 1952b. In that article, Friedman set out to demonstrate "that an alleged 'proof' of the superiority of the income tax [over the excise tax] is no proof at all, though it has repeatedly been cited as one." Friedman presents two goods, $\mathrm{X}$ and $\mathrm{Y}$, and then assumes an excise tax (entirely shifted to the consumer) of 50 percent placed on good X. This tax (called Excise Tax A) results in a rotation of the budget constraint and a new equilibrium consumption bundle. He then supposes that, instead of the excise tax, an income tax (called Income Tax A) is imposed to yield the same revenue. This shifts the original budget constraint in, where it crosses the equilibrium bundle of the excise tax. The budget constraint resulting from Income Tax A offers a higher level of utility than the budget constraint resulting from Excise Tax A, and thus the income tax is preferable.

To demonstrate the alleged fallacy of this proof, Friedman assumes that Excise Tax A is already in effect. He then assumes that a second excise tax of 50 percent (called Excise Tax B) is placed on good Y. Using the same reasoning as before, he demonstrates that placing an income tax that yields the same revenue (called Income Tax B) is preferred to the excise tax. Therefore, "Income Tax B plus Excise Tax A is preferable to Excise Tax B plus Excise Tax A.” Since placing a 50 percent excise tax on good $\mathrm{X}$ and good $\mathrm{Y}$ is the same as a 50 percent income tax, he argues that "Income Tax B plus Excise Tax A is preferable to Income Tax B plus Income Tax A." However, "when Income Tax B is removed from both sides," the result is that "Excise Tax A is preferable to Income Tax A." The contradiction of the original proof "follows rigorously" from the same argument. In his own note, Phipps (1952a) contests Friedman's paper by pointing out that it is incorrect to drop Income Tax B from both sides. The relative price of good $\mathrm{X}$ is higher when Excise Tax $\mathrm{A}$ is in effect than when Income Tax A is in effect. Therefore, the income tax removed from the left-hand side is a lighter tax than the income tax removed from the right-hand side.

Friedman's "Reply" (1952a) immediately followed Phipps's paper in that issue of the Journal of Political Economy. In it, Friedman began by saying that "Professor Phipps is entirely correct that my attempted 
reductio ad absurdum of the usual excise-tax-income-tax argument is a dud" (334). Nevertheless, he goes on to say that "Phipps is entirely wrong in supposing that this inexcusable blunder affects the validity of the rest of my paper . . . yet [that particular argument] is only a flourish, not an essential part of the analysis, and it can be deleted bodily with only minor verbal changes in the rest of the paper" (335).

From the public record we seem to have a straightforward case of an individual who happened to be a mathematician, writing some short comments and corrections to some papers written by economists on quite diverse subjects. Although he seemed to be writing on minor points not directly related to the papers' real contributions, Phipps seemed to have a respectable engagement with the mathematical economics literature, at least as a close reader of the written text. Just as one of our colleagues assigns graduate students in his International Trade course to find minor errors in published papers and to pen "A Comment on $X$ " for part of the course grade, so too does Phipps impose on himself the assignment to write comments on mathematical errors in economics papers.

\section{On Mathematics and Economics}

The presence of mathematics in economics is not a recent phenomenon. In justifying its use, economists have frequently described mathematics as a tool that facilitates the analysis and exposition of an economic problem. According to this widely held view, mathematics offers another way of stating an economic theory, and one can (and should) clearly translate between the mathematical model and the economic model. As early as 1838 we see Augustin Cournot defending his work by remarking that

the importance of mathematical symbols is perfectly natural when the relations between magnitudes are under discussion; and even if they are not rigorously necessary, it would hardly be reasonable to reject them, because they are not equally familiar to all readers and because they have sometimes been wrongly used, if they are able to facilitate the exposition of problems, to render it more concise, to open the way to more extensive developments, and to avoid the attractions of vague argumentation. (Cournot [1838] 1963, 2)

By the late nineteenth century the linking of mathematics to economics was seen as a means of establishing economics as a science. 
Alfred Marshall's long war of attrition to establish an Economics Tripos in the Cambridge system is a testament to this connection, yet Marshall, although eager for mathematical connection and a former Second Wrangler himself at Cambridge, was increasingly disconnected from the world of mathematics as it was bursting forth in new areas outside of late Victorian England. By the time he was sixty-three, with his powers diminishing ("I never read mathematics now: in fact I have forgotten even how to integrate a good many things" [Whitaker 1996, 130]), he penned the famous letter to Arthur Lyon Bowley in which he advised Bowley to "(1) Use mathematics as a short hand language, rather than as an engine of inquiry. (2) Keep to them till you have done. (3) Translate into English. (4) Then illustrate by examples that are important in real life. (5) Burn the mathematics. (6) If you can't succeed in 4, burn 3" (Whitaker 1996, 130).

Our interest is with the treatment of mathematics in economics in the middle of the twentieth century, when the correspondence between Patinkin and Phipps takes place. By this period, Marshall's translation metaphor has taken root in Samuelson's view that "mathematics is a language." But Samuelson's view is not an isolated one. The translation metaphor is also a central theme of Tjalling Koopmans's famous 1957 essay "On the Interaction of Tools and Reasoning in Economics," in which Koopmans presents mathematics as a tool to be used to solve, or facilitate the solving of, economic problems, which are distinct from the mathematical tools themselves:

While "problems" are to some extent posed by conditions and needs of society, "tools" and states of training in the use of tools are part of the personal equipment of the investigator. It is true that it is already difficult, at best, to be objective about what are valid answers to a given social or economic problem. . . It is even harder to be objective about what are promising tools for unsolved problems: the usefulness of our own individual minds and of the investments of personal effort sunk in our training and direction of interest are involved. (Koopmans 1957, 170)

Koopmans here employs a powerful and often compelling image of mathematics, in which it is one of several tools he considers (among statistics, computer programs, etc.): mathematics is a distinct body of knowledge to be employed to solve problems in a separate body of knowledge. Just as a hammer is not a building, but can be employed 
to build one, mathematics is not economics, although it can be used to construct an economic argument. Better hammers, and knowledge of how they can be used, may allow better structures to be erected.

The belief in the translation of mathematics is often accompanied by a view that the language of mathematics is useful in describing an autonomous economic reality. This view surfaces in Koopmans's characterization of "economic theory as a sequence of models":

Each model is defined by a set of postulates, of which the implications are developed to the extent deemed worthwhile in relation to the aspects of reality expressed by the postulates. The study of the simpler models is protected from the reproach of unreality by the consideration that these models may be prototypes of more realistic, but also more complicated, subsequent models. The card file of successfully completed pieces of reasoning represented by these models can then be looked upon as the logical core of economics, as the depository of available economic theory. (Koopmans 1957, 142-43)

We study the mathematical model in lieu of the economic substrate directly, perhaps because the model allows difficulties to be separated out and addressed seriatim in increasing complexity. ${ }^{8}$ The image, for that is what it is, is that of a map of a region as a representation of the region different from that region, a picture as a representation of an object different from the object. A mathematical model is a metaphor for the economic problem under investigation, an $\mathrm{X}$ that is considered as a Y. In mathematical terms (!), the structures of $\mathrm{X}$ and the connections in $\mathrm{X}$-the mappings associated with $\mathrm{X}$-are themselves mapped consistently on $\mathrm{Y}$ and $\mathrm{Y}$ 's mappings. $\mathrm{X}$ and $\mathrm{Y}$ are homeomorphic: $\mathrm{X}$ is relevantly like Y. It is not, however, easy to make sense of "relevantly like."

At about the same time that Koopmans was writing his essay, another future Nobel laureate was setting out his views on the topic. In a series of lectures that George Stigler delivered at the London School of Economics in 1949 (Stigler [1949] 1969), the fourth—“"The Mathematical Method in Economics"-provides an interesting window on the role of mathematical economics at mid-century. Stigler was not, of course,

8. These early views on models prefigure some interesting recent work by philosophers and historians of economics (see Morrison and Morgan 1998). 
trained as a mathematician, but he had reasonably sophisticated knowledge of at least quantitative methods in what would come to be called applied economics/econometrics, and his view of mathematics is one that was widely shared at the time of his writing. "Because mathematics is the premier language of logic, it is a method: a method of drawing exact deductions from given premises, and of verifying the logical consistency and adequacy of the premises. It follows that mathematical economics is a thing without content" (37). Stigler comments in a footnote that "the layman's appreciation of mathematics must necessarily be based upon authoritative hearsay; I have found R. Courant and H. Robins, What is Mathematics? especially illuminating" (37). This idea that mathematics itself lacks content expresses much the same idea as mathematics is a language, not a set of referents.

Stigler sets as his task his "wish to explore special claims for the mathematical method, claims that transcend its admitted power and usefulness" (38). He argues that it does not necessarily lead to good economic theory, nor does mathematical exposition have an inherent clarity. Stigler rejects the claim that "the mathematically trained economist states his concepts more clearly, on average, than the unmathematical economist" (40), although he concedes the claim that "in certain types of [economic] analysis, the mathematical method is indispensable" (40).

On balance, Stigler wishes to argue that a mathematical structure of economic analysis must be based upon an analysis of uniformities in the subject matter:

In the present early stage of economic study, the economist as scientist must be largely occupied with the isolation of these uniformities in his subject matter. . . . until we possess many uniformities, we cannot erect broad analytical systems which are likely to be illuminating in the areas where uniformities have not yet been isolated. This is true because it is a variety of uniformities calling for systematization that gives rise to a useful analytical system. (41)

We see here again an almost naive realist view of science, one which had been problematized long ago by individuals like Ludwik Fleck, Gaston Bachelard, Pierre Duhem, and Karl Popper: the idea of a preexisting economic world that could be described independently of any description, identified independently of any identification, represented directly and clearly independently of any representation, held real sway among most economists (and perhaps it still does!). In this view, economies 
"are," and economics "is," and mathematics is a nonnatural mode of analyzing "it." Stigler's solution to these problems involves first that economists study more mathematics (although this presents the problem of substituting at the margin, as it is the study of economics which must be substituted against). But second, "in his publications the mathematical economist can provide along with his equations a translation of his results into words" (Stigler [1949] 1969, 44; emphasis added). His penultimate paragraph sounds the call:

The mathematical economist can, if he wills, always meet this obligation. Even when the details of the proof must be shrouded in a fog impenetrable to the nonmathematical economist, the assumptions and the conclusions can always be stated clearly in the language of words, and heuristic derivation of the conclusions is probably always possible. The failure to provide these translations is a renunciation of the canons of scholarship.... the queen of the sciences should not be made a puppet of a scientific oligarchy. (45; emphasis added)

Although Stigler, in this essay, paused at one point to chastise Samuelson, Stigler's view of mathematics is fully consistent with Samuelson's approval of the idea that "mathematics is a language." With this metaphor, Stigler is right to call for translation, for it is as if the economist of mathematical inclination is simply writing in Russian, or Chinese, or, for that matter, Martian, if such a language existed. (Of course this discussion begs the entire question of whether mathematics, if it were like Russian or any other ordinary language, could be translated at all, for there is a huge literature on the nature and meaning of translation difficulties and on how there are always losses, often major losses, in language translation.)

In any event, we see that those involved in mathematical economics during the middle of the twentieth century viewed mathematics as a tool for describing an autonomous economic reality: they believed that even as mathematics clarifies economic reasoning, it nonetheless is a specialized language that can (and many say, should) be translated into ordinary language.

In opposition to this view is our belief that mathematics is a separate and distinct set of discursive practices and arguments, in which Thomas Kuhn's incommensurability problem occurs in spades, and 
translation fails necessarily. 9 The correspondence between Patinkin and Phipps offers a case study of communication between an economist and a mathematician. Of course we do not claim that Phipps is perfectly representative of the mathematical community at mid-century. Instead, we view the correspondence as an instance in which the translation metaphor is challenged in practice: at issue thus were such questions as "How are mathematical proofs evaluated in economics?" "What is the value of rigor in argument?" and "What is the proper role of mathematics in economics?"

\section{The Patinkin-Phipps Correspondence}

The correspondence between Patinkin and Phipps concerns Patinkin's "Relative Prices, Say's Law, and the Demand for Money" (Patinkin 1948) and Phipps's objections contained in "A Note on Patinkin's 'Relative Prices"” (Phipps 1950a). Patinkin was informed of Phipps's "Note" before its publication, and on 9 December 1949 he wrote Phipps to request a copy "in order to determine if a reply to your comments is in order." Thus began a protracted, and sometimes heated, correspondence on the validity of the mathematical proof used in Patinkin 1948.

Patinkin (1948) examined the generalized Walras-Pareto classical model that considered a monetary economy. He claimed that, by assuming people do not derive utility from holding money, the classical model is consistent only if there are no stocks of money. This implies that the classical system does not determine absolute prices. Patinkin went on to argue that introducing money into the utility function represents the satisfaction derived by individuals from holding money as a means of dealing with uncertainty. The implications of assuming that money is in the utility function are that it is impossible that all the demand functions should depend only on relative prices, and it is impossible for Say's law to hold.

9. According to Kuhn's view, episodes of paradigm shifts lead to partial breakdowns in communication between the proponents of different theories. In The Structure of Scientific Revolutions (1970), Kuhn writes that "the proponents of competing paradigms practice their trades in different worlds. . . . [They] see different things when they look from the same point in the same direction. . . . Both are looking at the world, and what they look at has not changed. But in some areas they see different things, and they see them in different relations one to the other" (150). As mathematics and economics are different disciplines, not simply alternate paradigms within a discipline, it is not Kuhn but rather Stanley Fish's (1980) modification of Kuhnian incommensurability that we adapt to our argument. 
Phipps's criticism (1950a) focused on Patinkin's proof that the classical system is consistent only if there are no stocks of money. After establishing the equilibrium conditions for the classical pure exchange economy, Patinkin then considered the implications of extending the classical system to a monetary economy. The classical system holds that people do not receive utility from holding paper money, so an individual will not plan to hold any money at the end of a given period. Thus the budget constraint of the classical system must be restated as

$$
\sum_{j=1}^{n-1} p_{j} Z_{j a}=\sum_{i=1}^{n} p_{i} \bar{Z}_{i a},
$$

where the left-hand side represents the product of the consumption flow of the goods and the prices of those goods, summed over the $n-1$ goods. Good $n$ is paper money, which is not included in the left-hand side of the budget constraint since the classical system assumes that people do not hold any money at the end of the period. The right-hand side represents the product of the initial stocks of the goods and the prices of those goods, summed over the $n$ initial stocks. The summation on the righthand side runs up to $n$, since there is no reason why the individual's initial stocks should not include money. Patinkin assigns the $n^{\text {th }}$ good, paper money, as the numeraire (i.e., $p_{n}=1$ ). According to Patinkin (1948, 141), "This modification of the budget restraint is the crux of the entire argument. Consequently, though it is intuitively quite obvious, I shall prove it rigorously." Patinkin derives the first-order conditions and imposes the equilibrium condition that the excess demand functions (the difference between the consumption flow of a good and the initial stock of the good, summed over all individuals) must be zero. He claims that the only way this equilibrium condition can hold (i.e., the classical system is consistent) is if the initial stock of money for each individual is zero.

This inconsistency of the classical system, wrote Phipps, "is obtained by his use of a set of assumptions which can readily be shown to be contradictory" (1950a, 25). Phipps claimed that Patinkin's contradictory assumptions are the following: (1) people derive no utility from paper money and therefore money does not enter the utility function; and (2) the price of money relative to useful goods is one. "Using these contradictory assumptions," claimed Phipps, "Patinkin finds it quite easy to show the system under discussion to be inconsistent" (26). 
On 30 December 1949 Patinkin wrote to Phipps defending his assumptions, arguing that they were not mutually contradictory. 10 His defense of his proof employs a traditional line of argument in monetary economics:

Perhaps I can make this clear by a simple counterexample drawn from history: In England, for a long period, the guinea existed as a unit of account, without there being any in circulation. Now, clearly the price of a guinea was one (guinea); yet no-one held any quantities of guineas and nobody wanted to. The fallacy in your proof is that you do not take account of such a commodity: That is, a commodity in which there are not stocks in existence. If you will consider such a commodity, you will see that you cannot carry through the line of your argument.

On 9 January 1950 Phipps responded with a slight modification of his original argument. He now considered the possibility that there can be a good with positive price for which an individual has no demand or supply. However, he says, "This example is slightly different from your paper money. In your [classical monetary system] none (no single one) has a demand for money; it is a closed economy with [demand for money] equal to zero for all [individuals]. How then can one 'sell' his money if he has any?" Phipps also claims that Patinkin's English guinea analogy is inaccurate. He wrote, "We have the same thing here in the USA; our eagle is a \$10-goldpiece which is not allowed to circulate. It has its equivalent in ten silver dollars which do circulate and can be used to buy food, clothing and shelter. The same remark applies to the guinea; 21 silver shillings, its equivalent, would buy, or could be exchanged for, a desirable good."

On 20 February 1950 Patinkin defended his guinea example. He wrote:

I still insist that the example of the guinea is a perfectly good one. . . The fact that a guinea is defined as 21 shillings affects only the determinacy of the system; it has nothing to do with the consistency. I think that you are being misled here by the word "equivalent." You certainly do not mean that a guinea has a value of one because it is "equivalent" to-in the sense that it can be exchanged for- -21

10. All references to the Patinkin-Phipps correspondence shall be understood to be to items in the Don Patinkin Papers in the Special Collections Library of Duke University. 
shillings. A guinea does not exist; hence, it cannot be exchanged for anything.

Unlike Phipps, we economists sympathize with Patinkin's frustration. The idea that a numeraire can be fictitious, like "the price level," or the price of a unicorn, is not a difficult idea; it is just one not grounded in ordinary language. Phipps may not like the game Patinkin is playing, but it is hardly inconsistent, let alone incoherent.

For that reason, it is a clearly annoyed Patinkin who questioned, on 16 February 1950, Phipps's ability to examine the mathematical soundness of economic work. He suggests that economics is not equivalent to mathematical reasoning since economics cannot readily be translated into mathematical form. One needs a background in economics before one can appeal to mathematics:

Your general objective of surveying mathematical economic literature from a rigorous viewpoint is very commendable. However, to accomplish this objective it is necessary to understand the purposes for which the economist is using the mathematical analysis. This should not be misinterpreted as saying that economic reasoning will make incorrect mathematics correct. But it definitely is intended to imply that failure to understand the economic background of the problem under discussion may well lead (as it has led in the three papers you sent me) to mathematical errors. I should imagine that a pure mathematician would hesitate to pronounce definitive judgment on a question in mathematical physics without first thoroughly investigating the physical conditions involved; I think the same should be true for mathematical economics. To reverse your dictum, writers on economic questions should be held responsible for an understanding of economic analysis.

On 9 March 1950 Phipps defended the right of mathematicians to examine work in applied fields. He held that economics can be translated into mathematical language. One can argue about correct translation, but not about sound mathematical reasoning.

If we take any economic question as an example, the problem raised by this question translates into certain mathematical language. Sometimes there may be a difference as to the exact translation; in that case, one should consider the alternate possibilities. Once the problem is posed in mathematical language, it should be possible to reach 
definite conclusions or sets of solutions. In economics and in mathematical physics, the mathematician is prepared to say definitively, "if these are the initial equations, then this is the final result."

Thus, according to Phipps, economic background is not important except as it serves to help in the translation to and from mathematics. He admitted that "it is easily possible, of course, for one to describe in words one problem and, in effect, to translate another. This error occurs much too frequently in all fields of applied mathematics."

Patinkin persisted in his claim that one must first have a firm understanding of economics before engaging in mathematical reasoning of economic issues. In a letter dated 18 March 1950 he wrote:

I quite agree with you that it is shocking that any published paper should contain mathematical errors. But I think there is something even more important than that. I think it is fundamental that any paper which has any pretenses of being a serious scientific work should be free of misinterpretations, misunderstandings, and misrepresentations. This is especially true of a paper which attempts to criticize the works of others. If the paper makes it patently obvious that the critic has made no serious attempt to read and understand carefully the text which he purports to criticize, then this is [the] most heinous crime that can occur in the intellectual world.

Patinkin then tried to turn Phipps's beliefs about the nature of mathematics against him.

[In] your last letter to me you state quite correctly (and how you ever interpreted me as saying anything to the contrary is a mystery to me) that the mathematician should only take a given system of equations and determine its solutions; it is not his job to go into the background of these equations in the non-mathematical fields from which they originate. But immediately afterwards, when put to the test, you reject the criteria you yourself have just set up. [The classical monetary system I set up] is a mathematical system; where it came from is no business of the mathematician; the only question he is called upon to answer is: Is this system . . . necessarily inconsistent?

Phipps attempted to find middle ground by agreeing that a critic should make a serious attempt at understanding the text. Nonetheless, in a letter written on 25 March 1950 he claimed that Patinkin does "not leave room for the possibility that the author may not have been 
clear, for various reasons. Hence, a paper may not be understandable; or it may possess several interpretations; or again it may contain a flaw overlooked by the author." With regard to Patinkin's argument on the classical monetary system, Phipps wrote:

I can only repeat the argument of my note and conclude that the price of this good [paper money], relative to goods which still have marginal utility, is zero!!!! On this point I am willing to stake the whole argument. Do you still maintain that the stated conclusion does not follow from the stated assumptions? Or do we differ as to what those assumptions really are? This point seems to be the actual basis for our differences. Until it is settled, neither of us will accept the criticism of the other.

In his reply on 12 April 1950 Patinkin again asserted that an understanding of economics is necessary before one can adequately criticize economic work.

I am firmly convinced that you and your group must spend at least one or two years learning the basic fundamentals of mathematical economics before any worthwhile criticism will be forthcoming.

In this letter, he again addressed Phipps's claim about the contradictory assumptions, this time by turning the argument on its head. While Phipps argued that Patinkin's assumptions are contradictory and therefore lead to a proof of inconsistency, Patinkin countered that under his assumptions it is possible for the system to be consistent; thus the assumptions must not be contradictory. He claimed that the point of his argument is that the system is consistent only when money stock is equal to zero.

You claim that the assumptions of [the monetary classical system] are inconsistent. What does this mean? It means that it is impossible to derive a system from these assumptions which will be consistent. Thus in order to find out if $m y$ assumptions . . . are inconsistent we must take my assumptions and see if they lead to a system which is necessarily inconsistent. ... Now, what you must do in order to make your point is to show that this system under my assumptions-specifically, under the assumption that [the price of money is one], must always be inconsistent. For this is the meaning of your assertion that my assumptions are inconsistent. But you cannot demonstrate this; for as 
the theorem . . . explicitly points out, if [money stock is zero], the system might be consistent. Hence your argument falls to the ground.

On 1 May 1950 Phipps defended his assessment of Patinkin's assumptions with a discussion on (1) the consistency or inconsistency of a set of postulates and (2) the dependence or independence of a set of postulates.

The dependence or independence of a set of postulates can, in theory at least, be demonstrated logically. If any postulate of the set can be derived as a theorem from others of the set, it is dependent upon them and should not logically be classified as a postulate. On the other hand, if a situation can be created whose conditions satisfy all postulates but one, or which contradicts only one, then that one is shown to be independent of the others.

The consistency or inconsistency of this set is not so easily dealt with. In the first place, it is never logically possible to prove the consistency of a set of postulates. It is therefore useless to assume the consistency of the set... since it is never possible to know for certain if this postulate is itself consistent with the others. Assuming consistency does not make it so. The best that anyone can do is to avoid any demonstrable inconsistency.

The matter of inconsistency is more definite. If it can be shown that a group of one or more postulates requires (not just permits as mentioned before) a certain conclusion which is contradicted, in whole or in part, by another postulate, then that other postulate is inconsistent with those of the group. In other words, the set is demonstrably inconsistent.

In this latter category, I place your assumption ... that [the price of money] is one.

Phipps also claimed that Patinkin was incorrect in asserting that one must show that the set of assumptions must always lead to inconsistency.

My statement implies much less; it implies that some conclusions drawn from this set of assumptions may fail to hold or may be inconsistent with other conclusions. . . . My statement admits the possibility of the given condition (inconsistency); your statement makes 
the condition mandatory. My statement allows the alternate possibility of deriving from these assumptions a system of conclusions which among themselves are consistent; your statement does not. The stronger statement of yours has no logical foundation. . . . My argument does not fail since it admits the possibility of a limited consistent set of conclusions derivable from these inconsistent assumptions. My argument states that, since your assumptions are demonstrably inconsistent, there is the ever-present danger that a derived conclusion will be found inconsistent either with certain of the original assumptions or with other derived conclusions.

On 1 June 1950 Patinkin suggested that the discussion was leading nowhere. He wrote, "I really do not think there is any point carrying on the discussion any further on this issue. I have made myself as clear as I possibly can be in my last letter to you, and there is nothing I can add to it." He does make one last attempt, however, at explaining their differences:

What concerns me at the moment is your treatment of [the] equation in which I say that the demand for money is identically equal to zero. (Incidentally, you repeatedly refer to this as an assumption of my system. This is absolutely not true. As you can see quite clearly ... it is an implication of the assumptions of [the system].) ... The statement that the demand for money is equal to zero identically in the prices is a meaningful statement. Economists expect economic variables to be dependent upon prices. This statement tells us that in [the classical monetary system] the demand for money has this property, that it is always zero regardless of what the prices may be. For an economist, this is an important piece of information.

Over a year later, in early September 1951, Phipps and Patinkin met in Chicago to discuss their disagreement. However, there was no resolution. On 18 September 1951 Phipps picked up the correspondence once again.

You seem to believe, and lead the reader to suppose, that your system is the only one possible on mathematical grounds in which the utility functions do not contain money. However, there are others . . . ; for example, there is a system in which [price of money equals zero], a system which you violently reject. 
Thus, you have placed an "iron curtain" around your solution. The reader is never told that there are many others which satisfy the broad conditions of the problem. And finally, you have arrived at your conclusions by calling things by their wrong names and giving the wrong reasons for reaching these conclusions.

Phipps of course was correct, although the Stalinist "iron curtain" allusion is rather on the edge of good taste. The system with which Patinkin was concerned had a context, a history, and an established place in the discursive practices of monetary theorists. It was not in fact an arbitrary system, but rather one in which certain distinctions could be made (numeraire money, money of account, fiat money, money as an asset, etc.). That Phipps saw correctly that Patinkin's system was not unique, though, was of little consequence. Alternative assumptions, which seemed to satisfy logical coherence requests, were in fact economically incoherent, meaning that economists simply were not concerned with them. It is similar in fact to the kind of demand analysis put forward in Griffith Conrad Evans's Mathematical Introduction to Economics (1930), which argued that utility theory was meaningless, and which simply postulated various closed form demand functions at the market level. Economists simply ignored such a discussion, disconnected as it was from their own analytic, and discursive, practices (Weintraub 1998).

The correspondence on this issue ended on 5 January 1952 when Patinkin wrote:

I do not think that there is any point in writing a detailed criticism of your letter. In it you continue to insist on misinterpreting arguments which to me seem to be quite clear. I was not able to make these points clear during the long evening which we spent together in Chicago. I doubt very much that I shall be able to do so by means of correspondence.

Neither with a whimper, nor a bang, did thus Patinkin break off the correspondence. The issues indeed never were joined, perhaps because neither could adopt the other's perspective. One of the exercises psychologists use to break a communication impasse between two individuals is to have each argue the other's position, to have them switch perspectives, as it were. Seeing an issue as another sees it is empathetic understanding, and such empathy sometimes inclines one to change one's mind. If, 
however, neither can see the opponent's argument, cannot state it fairly, cannot appreciate the contingent circumstances from which it arises and takes on both coherence and merit, communication is doomed.

Although, in his final letter, Patinkin finally dismisses Phipps, it is striking that Patinkin allowed the correspondence to continue as long as he did. ${ }^{11}$ Such patience may be attributable to Patinkin's early schooling at a yeshiva. As he writes in the postscript of "The Training of an Economist," the years in the yeshiva instilled in him "the patience to spend hours reading and rereading a difficult text in the Talmud, paying attention to its context, and to the nuances and minor differences of phrasing that provide clues to its meaning" (388). This experience further instilled in him "the confidence that if I were patiently to read and reread a text in economics in this way, I would eventually succeed in penetrating to its meaning, in understanding the intent of its author" (388). This leads one to ask whether Patinkin ever did understand Phipps's intent.

It is possible that Phipps's criticisms did have some residual effects on Patinkin's future work. In the preface of his Money, Interest, and Prices, Patinkin comments on the debate that took place in the journals regarding his first two articles. "Needless to say, the necessity for preparing these replies was an invaluable stimulus toward a constant reworking and improving of the argument and its exposition" (1965, viii). He does not, however, mention Phipps by name. Perhaps recalling Phipps's criticism of the numeraire, Patinkin later in the book differentiates between money as an abstract unit of account and fiat paper money. The former "serves only for purposes of computation and record keeping. This unit has not physical existence; that is, it does not coincide with any of the goods which exist in the economy" (18). Patinkin then uses the same example that he expressed to Phipps: "Perhaps the most familiar [example of abstract money] is the guinea in present-day England" (19). If this was an effort to address Phipps's criticisms, the effort was lost on Phipps. In response to the publication of Money, Interest, and Prices, Phipps, in a letter dated 23 October 1957, took the time to contact the publisher of the book to voice his displeasure with the quality of Patinkin's work.

11. Phipps once initiated a correspondence with Nicholas Georgescu-Roegen concerning what Phipps perceived to be the use of faulty mathematics in Georgescu-Roegen's work. Georgescu-Roegen ended the correspondence after two letters (Georgescu-Roegen Papers, letters dated 27 September 1952 and 23 October 1952). 


\section{Conclusions}

The belief that mathematics is a language that can be translated into economic implications held sway in the middle of the twentieth century. The correspondence between the economist Don Patinkin and the mathematician Cecil Phipps provides one case in which the relationship between mathematics and economics is more complex than is suggested by the mid-century mathematical economists. 12 Economists and mathematicians are trained in different discursive practices, each containing unique (although perhaps overlapping) persuasive techniques and rules of assessing evidence. The correspondence between Phipps and Patinkin demonstrates that these differences at times make it difficult, if not impossible, to resolve disagreements about the validity and application of a mathematical proof in economics.

The difficulties experienced by our protagonists arise because the different communities of mathematicians and economists do not share histories, training, techniques of persuasion, rules for assessing evidence, or even languages. As Stanley Fish presents it, "Interpretive communities are made up of those who share strategies not for reading but for writing texts, for constituting their properties.... [Moreover] since the thoughts that an individual can think and the mental operations he can perform have their source in some or other interpretive community, he is as much a product of that community (acting as an extension of it) as the meanings it enables him to produce" (Fish 1980, 14). Understanding that "texts" here are to be understood as the material products of these communities, their theorems, descriptions, analyses, arguments, and so forth, we can appreciate how economists' understanding of the role of mathematics is associated with their socialization as economists. That is, the discursive practices that emerge from the training economists receive are different from those of mathematicians, and this itself may make resolving disagreements between economists and mathematicians on the validity and application of a mathematical proof difficult if not impossible. Their conceptual frameworks are effectively incommensurable.

Phipps, who was not an economist, could not see or understand the context in which one assumption was acceptable in economics and

12. Of course the relationships between John von Neumann and Oskar Morgenstern, as well as between Leonard Savage and Milton Friedman, offer other cases (with possibly different implications) of communication between mathematicians and economists. 
another was not. Patinkin, who was not a mathematician, could not appreciate the content-less approach to ideas of consistency and inconsistency, or the belief that one had freedom to choose among alternative axiomatizations in order to produce mathematically interesting results. Despite their mutual talk of "translation," neither spoke the other's language. More than conceptual incommensurability was involved. With apologies to the Captain in Cool Hand Luke, "What we have here is [more than] a failure to communicate": for the failure was necessary and the incommensurability was multilayered and inevitable. Socialized differently, educated differently, with different knowledge of monetary theory and mathematics, and with different objectives in argument, each worked with a different boundary between economics and mathematics, and so each conceived of mathematical economics differently. For Patinkin, mathematics could be used in an autonomous economics to formalize economic arguments, and to facilitate the making of rigorous deductions. For Phipps, mathematics was the dopplegänger for all discursive practices that presumed to argue from assumptions to conclusions: any such argument could be translated into mathematical terms - provided with an interpretation in mathematics — and be made rigorous thereby, or be shown to be incoherent. Phipps's view prefigured the position attributed decades later to the Bourbakist Renè Thom, who claimed (defending catastrophe theory) that "in the future, only mathematicians will have the right to be intelligent." 13

\section{References}

Allen, R. G. D. 1938. Mathematical Analysis for Economists. London: Macmillan. American Men of Science. 1955. New York: R. R. Bowker Co.

Arrow, Kenneth J. 1954. A Review of "Money in the Utility Function." Mathematical Reviews 18:18366h.

Boles, Ralph C. 1998. Telephone conversation with E. Roy Weintraub, 2 January.

Courant, Richard, and Herbert Robbins. 1941. What Is Mathematics? An Elementary Approach to Ideas and Methods. London: Oxford University Press.

Cournot, Augustin. [1838] 1963. Researches into the Mathematical Principles of the Theory of Wealth. Translated by Nathaniel T. Bacon. Reproduction of the 1927 Macmillan edition. Homewood, Ill.: Irwin.

Ehrlich, Paul. n.d. Mathematics at the University of Florida in Gainesville. http://www.math.ufl.edu/ theral/mathhist.html.

13. Or is said to have claimed. See the discussion of the Thom "claim" in Woodcock and Davis 1978. 
Evans, Griffith C. 1930. Mathematical Introduction to Economics. New York: McGraw-Hill.

Fish, Stanley. 1980. Is There a Text in This Class? Cambridge: Harvard University Press.

Friedman, Milton. 1952a. A Reply. Journal of Political Economy 60:334-36.

- 1952b. The "Welfare" Effects of an Income Tax and an Excise Tax. Journal of Political Economy 60:25-33.

Georgescu-Roegen, Nicholas. Papers. Duke University Library.

Hicks, John R. 1939. Value and Capital. Oxford: Oxford University Press.

Ingrao, Bruna, and Giorgio Israel. 1990. The Invisible Hand: Economic Theory in the History of Science. Cambridge: MIT Press.

Koopmans, Tjalling C. 1957. Three Essays on the State of Economic Science. New York: McGraw-Hill.

Kuhn, Thomas S. 1970. The Structure of Scientific Revolutions. 2d ed. Chicago: University of Chicago Press.

Lytle, Ernest, Jr. 1998. Telephone conversation with E. Roy Weintraub, 25 May.

Mazeres, Reginald. 1998. Telephone conversation with E. Roy Weintraub, 2 January.

Miller, William G. 1951. The Mathematics of Production and Consumption in a Static Economy. Ph.D. diss., University of Florida.

Mirowski, Philip. 1989. More Heat than Light: Economics as Social Physics: Physics as Nature's Economics. New York and Cambridge: Cambridge University Press.

Morrison, Margaret, and Mary S. Morgan, eds. 1998. Models as Mediators. Cambridge and New York: Cambridge University Press.

Patinkin, Don. Papers. Duke University Library.

— 1948. Relative Prices, Say's Law, and the Demand for Money. Econometrica 16:135-54.

- 1949. The Indeterminacy of Absolute Prices in Classical Theory. Econometrica 17:1-27.

-1965. Money, Interest, and Prices. 2d ed. New York: Harper.

- 1981. Essays on and in the Chicago Tradition. Durham, N.C.: Duke University Press.

- 1995. The Training of an Economist. Banca Nazionale del Lavoro Quarterly Review 48.195:359-95.

Phipps, Cecil G. 1928. Problems in Approximation by Functions of Given Continuity. Ph.D. diss., University of Minnesota.

— 1950a. A Note on Patinkin's "Relative Prices." Econometrica 18:25-26.

- 1950b. A Note on Tintner's “Homogeneous Systems." Econometrica 18:63.

- 1952a. Friedman's "Welfare" Effects. Journal of Political Economy 60:332-34.

- 1952b. Money in the Utility Function. Metroeconomica 4:44-65.

Samuelson, Paul A. 1941. The Stability of Equilibrium: Comparative Statics and Dynamics. Econometrica 9:97-120. 
- 1947. Foundations of Economic Analysis. Cambridge: Harvard University Press.

Stigler, George J. [1949] 1969. Five Lectures on Economic Problems. Freeport, N.Y.: Books for Libraries Press.

Stoltz, M. P. 1951. Review of “A Note on Patinkin's Relative Prices.” Mathematical Reviews $11: 11530 \mathrm{~g}$.

Tintner, Gerhard. 1948. Homogeneous Systems in Mathematical Economics. Econometrica 16:273-94.

Weintraub, E. Roy. 1998. From Rigor to Axiomatics: The Marginalization of Griffith C. Evans. In From Interwar Pluralism to Postwar Neoclassicism, edited by Mary S. Morgan and Malcolm Rutherford. HOPE 30 (supplement): 227-59.

Whitaker, John K., ed. 1996. Towards the Close, 1903-1924. Vol. 3 of The Correspondence of Alfred Marshall, Economist. Cambridge and New York: Cambridge University Press.

Woodcock, Alexander, and Monte Davis. 1978. Catastrophe Theory. New York: Dutton. 